\title{
Desregulamentação do trabalho no Brasil: uma análise a partir da Política de Assistência Social
}

\section{Deregulation of labor in Brazil: An Analysis from the Social Assistance Policy}

\author{
Christiane Pimentel Silva*
}

\begin{abstract}
Resumo: Este artigo aborda a desregulamentação do trabalho no Brasil a partir da análise da Política de Assistência Social na atualidade. Com base nos fundamentos da exploração do trabalhador na sociedade burguesa e na precarização do trabalho no contexto da acumulação flexível, objetiva-se analisar o desmonte das políticas de seguridade social a partir da reforma do aparelho do Estado. No percurso metodológico utilizou-se de pesquisa qualitativa documental e da análise de dados estatísticos de agências oficiais do governo brasileiro, destacando-se a análise da Política de Assistência Social. Considera-se que a reconfiguração das políticas sociais por meio de atos normativos que repassam serviços públicos para a iniciativa privada e esfera pública não estatal, terminam por retirar conquistas no campo dos direitos sociais da classe trabalhadora e, especialmente, dos trabalhadores da política de assistência social.
\end{abstract}

Palavras-chave: Trabalho. Desregulamentação. Assistência Social.

\begin{abstract}
This article discusses the deregulation of labor in Brazil from the analysis of the Social Assistance Policy nowadays. Based on the foundations of the exploitation of the worker in bourgeois society and labor precariousness in the context of flexible accumulation, it aims to analyze the disassemble of the policies of social security from the reform of the State apparatus.In the methodological approach it was used documental qualitative research and statistical data analysis of official agencies of the Brazilian government, highlighting the analysis of Social Assistance Policy. It considers that the reconfiguration of the social policies by means of normative acts that pass on public services to the private sector and nonstate public sphere end by removing achievements in the field of social rights of the working class and, especially, the workers of the social assistance policy.
\end{abstract}

Keywords: Work. Deregulation. Social Assistance.

Recebido em: 11/03/2015. Aceito em: 02/03/2016

"Assistente Social (UFPA), Mestre em Serviço Social (PPGSS/UFPA), Docente da Faculdade de Serviço Social do Campus Universitário do Marajó-Breves, Universidade Federal do Pará. 


\section{Introdução}

Para Marx (1996), os mecanismos inerentes à forma salarial da produção capitalista impõem ao trabalhador condições de exploração, pois a produção capitalista tem seu fundamento precisamente no trabalho assalariado, isto ocorre porque esta categoria abrange a compreensão de que 1) o valor da força de trabalho diverge do valor que ela produz; 2) a força de trabalho produz valor e mais-valia para o comprador da força de trabalho; e 3) a complexidade total do trabalho assalariado compreende a metamorfose do dinheiro em capital. Esta condição de exploração é parte intrínseca da organização do trabalho sob o domínio do capital.

Entre os séculos XX e XXI, ocorreram significativas transformações sociais, econômicas, políticas e ideológicas para o ser social, entre as quais podemos citar as referentes às formas de trabalho, como a retração do mercado de trabalho regular e consequente inserção por meio de ocupações precárias. A contradição entre a relação capital-trabalho agrave-se mundialmente, a partir da década de 1970, com a reestruturação produtiva, fazendo surgir teorias que sustentaram a "crise da sociedade do trabalho", decretando o fim do trabalho (GORZ, 1982), na afirmativa de que o trabalho deixou de representar a categoria sociológica fundante do ser social (OFFE, 1989).

Outros autores discordam dessas explicações e oferecem outras respostas diante do atual crescimento da pauperização, como Antunes (2007), que defende que não ocorreu a perda de sentido ou de significado do trabalho e, sim, maior complexificação deste, que se torna ao mesmo tempo ainda mais intensificado nos seus ritmos e processos e socialmente combinado; ou como Alves (2007), que compreende uma reposição da lógica mercantil ${ }^{1}$ a partir dos anos 1970 (distinta dos trinta anos gloriosos), que desregulamenta e flexibiliza as condições de trabalho e assalariamento, atualmente denominadas de precarização do trabalho.

\footnotetext{
${ }^{1}$ De acordo com Alves (2007), ocorre uma "regressão" à etapa do capitalismo concorrencial, próprio do século XIX, quando a classe trabalhadora não possuía direitos sociais e trabalhistas. $O$ autor adverte que, embora a semelhança, o processo de precarização imposto ao trabalho no século XXI é mais perverso, na medida em que se desenvolve numa etapa mais avançada do processo civilizatório.
}

Na multiplicidade de questões que compõem as dimensões do trabalho em um quadro de intensas regressões nas conquistas da classe trabalhadora, o artigo se divide em dois momentos. No primeiro, sintetiza a compreensão marxiana de exploração do trabalho e enfatiza a grande expansão do desemprego estrutural, da precarização (desregulamentação) do trabalho e da ampliação do setor de serviços, na contemporaneidade. No segundo momento, compreende como as estratégias de intensificação do trabalho são incorporadas pela esfera estatal - historicamente, principal vínculo empregatício para os assistentes sociais.

A inserção profissional na política de assistência social foi tomada como parâmetro de análise das condições de trabalho do assistente social por ser uma das políticas públicas que mais emprega assistentes sociais (sendo a outra a área da saúde), de acordo com a pesquisa do CFESS realizada em 2004, "O perfil profissional do assistente social no Brasil", e também pelo processo de expansão a partir da Política Nacional de Assistência Social (PNAS/2004), que pode ser acompanhado a partir da pesquisa do Instituto Brasileiro de Geografia e Estatística (IBGE), intitulada Pesquisa de Informações Básicas Municipais (Munic) - Perfil dos municípios brasileiros/Assistência Social e a pesquisa do Ministério do Desenvolvimento Social e Combate à Fome (MDS) denominada Censo SUAS.

A partir desses elementos, considera-se que a precarização (desregulamentação) do trabalho na atualidade, é resultado dos mecanismos de superação da crise capitalista por meio de um novo padrão de acumulação mundializado, que acirram as contradições inelimináveis do sistema, que se expressam, principalmente, na recomposição de uma superpopulação relativa em proporções internacionais jamais vivenciadas no modo de produção capitalista (MPC), no rebaixamento salarial, na desregulamentação nas relações capital e trabalho, nos programas de ajuste estrutural e na adoção de políticas neoliberais, principalmente na América Latina.

O rebatimento desses processos da esfera produtiva, adentram a esfera estatal, analisados aqui, tomando-se a política de assistência social como referência, identificados em uma síntese que compõe o que se chama de precarização das condições de trabalho do assistente

114 Emancipação, Ponta Grossa, 16(1): 113-125, 2016. Disponível em <http://www.revistas2.uepg.br/index.php/emancipacao> 
social delineada por: 1) condições de trabalho e contratação dos assistentes sociais regidos pelas relações de terceirização/desregulação trabalhista em detrimento de contratos de longa duração; 2) a lógica burguesa de prestação de serviços, baseada no cálculo racional de metas meramente quantitativas, reforçando critérios de elegibilidade; 3 ) aumento na demanda por serviços socioassistenciais por parte da população pauperizada, principalmente em busca de programas de transferência de renda, mas que pelo número reduzido de equipes profissionais, não possibilita condições adequadas ao exercício profissional, condizente com as propostas do Projeto Ético Político Profissional.

\section{A exploração do trabalho pela ótica de Marx: o imperativo da produção de mais- valia ao capital}

Para Silva (2010), na principal obra de Marx, "O capital - crítica da economia política", o conceito de exploração do trabalho advêm do próprio mecanismo de assalariamento intrínseco à sociedade capitalista: as condições históricas de surgimento do modo de produção capitalista, necessitaram de um momento ímpar, em que de um lado, o trabalhador tornou-se "livre"2 para vender sua força de trabalho no mercado e, de outro lado, existiu um comprador desta força de trabalho, que também é o possuidor dos meios de produção e subsistência.

No processo de trabalho, o ser social utiliza seus conhecimentos e habilidades, dimensões físicas e intelectuais, para desenvolver uma ação/ movimento, que objetivará algo novo na natureza (posto pela relação homem e natureza): o produto do trabalho, que atende a alguma necessidade humana e por essa característica pode ser vendido na sociedade burguesa. Após algum período de tempo (socialmente necessário), será materializada determinada quantidade de trabalho, e um valor será acrescentado ao objeto que se produziu. Caso seja o trabalho de um alfaiate, o resultado é uma determinada quantidade de camisas (MARX, 1996).

\footnotetext{
${ }^{2}$ Para Marx (1996), o capital expropria o trabalhador da produção de seus meios de sobrevivência para que não consiga sobreviver sem a venda de sua força de trabalho.
}

Sob o domínio da produção capitalista, o trabalhador se submete à condição de assalariamento, que consiste no pagamento realizado pelo tomador da força de trabalho ao trabalhador, por um determinado período de tempo em que o sujeito do trabalho emprega suas habilidades e conhecimentos na produção de mercadorias. $\mathrm{O}$ trabalhador não vende as mercadorias que produz ao burguês, e sim sua força de trabalho em movimento, empregada em uma jornada de trabalho, que se divide em duas partes: uma parte paga e uma outra parte que não é paga ao trabalhador.

Na primeira parte da jornada de trabalho, 0 trabalhador cria produtos para trocar pelo equivalente de sua força de trabalho, seu salário produz mercadorias cujo valor equivalem a sua subsistência. O segundo período da jornada de trabalho corresponde a um tempo excedente para o trabalhador, uma parte não-paga em que o trabalhador continua produzindo as mercadorias que serão vendidas na esfera de circulação. Tanto as mercadorias criadas no período da jornada necessária, quanto as mercadorias geradas na jornada excedente são convertidas em valor no momento de sua venda, mas o sobreproduto é convertido um valor que é dado de graça ao capitalista pelo trabalhador.

No modo de produção capitalista, a inovação do assalariamento é dada pelo ocultamento do período excedente da jornada de trabalho, num período de sobretrabalho, para utilizar o termo de Marx (1996). Esse sobretrabalho produz um sobreproduto que não pertence ao trabalhador e nem produz para ele qualquer valor. Da mesma forma, este sobreproduto não custa nada ao capitalista, pois seus custos de produção foram pagos na primeira parte da jornada do trabalhador e, assim todo o produto excedente criado na segunda parte da jornada de trabalho constitui mais valor ao capitalista, acumulação de capital, o que o autor denominou de mais-valia.

Quando o produto do trabalho se converte em dinheiro, o trabalhador recebe apenas uma parte do produto que produziu, enquanto que, o capitalista conserva todo capital investido e se apodera gratuitamente de valor adquirido sem equivalente (mais-valia). Este processo é a própria acumulação de capital, que para Marx (1996), pressupõe a valorização do capital inicialmente investido mediante a produção de mais-valia. 
O capital precisa do constante processo de autovalorização e autoexpansão e por isso é imperativa a extração de mais-valia do trabalhador. Esta é uma imposição intrínseca à sobrevivência do próprio regime e, por isso, a produção e reprodução da "própria relação capitalista: de um lado o capitalista, do outro o trabalhador assalariado" (MARX, 1996, p. 211) deve ser constantemente reconfigurada. Enquanto as relações de produção forem mediadas pelo imperativo da extração de mais-valia, o capital resiste, contrariando muitas teses sobre um capitalismo humanitário, pois a mais-valia é a essência da exploração, da dominação e da opulência do capital às custas do trabalhador.

Para Marx (1996) a produção de mais-valia é resultado ineliminável (e imperativo) do processo de (re)produção capitalista e, portanto, o trabalho assalariado é a essência da exploração do trabalhador. O pagamento do trabalhador, o salário, é reproduzido pelo próprio trabalhador com o seu trabalho, e o trabalho assalariado, como dito antes não reproduz apenas seu próprio valor, mas também mais-valia.

\section{Alterações contemporâneas nas relações de trabalho}

Segundo Silva (2007), o processo de desqualificação e de precarização do trabalhador têm seu início na divisão manufatureira, quando o desenvolvimento das bases técnicas e/ou dos meios de trabalho ficam sob o domínio da relação capital-trabalho, pois os ofícios deixam de ser competência de um só trabalhador individual, que não mais detêm o conhecimento do processo como um todo, alterando a forma constituinte do trabalho artesanal.

A homogeneização do trabalho simples e desprovido de conteúdo se generaliza, contudo, diante da incorporação do mecanismo automáti$\mathrm{CO}^{3}$, na primeira grande crise do capitalismo em meados de 1873, quando a Inglaterra perde sua hegemonia industrial diante do emergente processo de padronização da organização do trabalho e da produção difundido pelos Estados Unidos,

\footnotetext{
${ }^{3}$ A mecânica substitui parcial ou totalmente a força física do trabaIho humano na atividade de transformação da matéria-prima em produto, garantindo o aumento da produtividade no processo de produção industrial.
}

dado pela associação dos princípios tayloristas aos métodos fordistas (MATTOSO, 1996).

Os princípios Tayloristas ou Teoria da Organização Científica do Trabalho, desenvolvida por Frederick W. Taylor (1856-1915) consistem na transformação dos tempos mortos da fábrica em tempos produtivos, por meio de técnicas de racionalização da produção operária, capazes de assegurar os objetivos capitalistas de máxima produção a custo mínimo. O principal obstáculo ao seu projeto era o know-how técnico que um artesão qualificado possuía, detido coletivamente pela corporação operária.

De acordo com Braverman (1987), as consequências mais evidentes da administração científica podem ser observadas na: a) máxima separação entre concepção e execução, ou seja, a dissociação entre trabalho manual e intelectual, dividindo-os em lugares determinados na cadeia produtiva e grupos de trabalho diferentes, restringindo-os a diferentes parcelas do mesmo processo de trabalho; b) centralização do poder nas mãos da direção, excluindo os operários da concepção e do planejamento produtivo; c) decomposição de tarefas a partir da destruição definitiva de ofícios e na adoção de tarefas simplificadas, que degradaram a capacidade técnica do trabalhador; d) análise de tempos e movimentos, que consistia em acompanhar a produtividade por meio do cronômetro e da avaliação de cada movimento, para se chegar a um tempo ideal e intensificar a produção; e) individualização de salários, seja por meio do salário por peça produzida, seja através do pagamento de prêmios adicionais aos que superem os níveis médios de produção, assegurando a competição entre os operários.

Os métodos tayloristas foram incorporados a Indústria Ford, em 1908, que inaugurou com o modelo $T$ de Henri Ford (1863-1947), a produção em massa. Essa produção se caracteriza pela criação de um sistema de medidas único para todas as peças, que tornou possível a linha de montagem, por meio de uma complexa

\footnotetext{
${ }^{4}$ Segundo Dejours (1992), a organização científica desapropria o know-how do artesão pela da decomposição do complexo modo operatório em gestos elementares, facilmente controlados por unidades. Assim, o artesão que dominava o conhecimento das várias etapas do processo produtivo, transformou-se em operário-massa, que por sua vez, possui a função de executar uma única e rotineira tarefa, perdendo sua liberdade de criação/invenção..
} 
e consistente intercambiabilidade das peças e na facilidade de ajustá-las entre si.

A linha de montagem de fluxo contínuo dado pela esteira, que fixava o trabalhador no mesmo local de trabalho, mas também impôs a execução de uma única tarefa, que pela repetição, ampliava o grau de especialização de cada operário e aumentava os ritmos de trabalho.

Harvey (2010), explica que a produção de massa necessitava de consumo de massa, ou seja, seria necessário uma nova política econômica capaz de dinamizar a reprodução da força de trabalho, que começou no governo de Frankin D. Roosevelt (1882-1945) nos Estados Unidos, com o New Deal, mas que ganhou relevância entre o fim da segunda Guerra Mundial e até o final da década de 1960, com a adoção das medidas keynesianas ${ }^{5}$ que consolidaram os "Anos dourados" do capitalismo (1945-1975) - também conhecido como Welfare State - numa onda longa de expansão econômica e de acordos coletivos com os trabalhadores em torno dos ganhos de produtividade do trabalho, que possuía três características essenciais, de acordo com Netto e Braz (2007, p. 199-201, grifos dos autores):

[...] o crédito ao consumidor, [...] reduziu a força daquela tendência [subconsumo das massas] e ampliou significativamente a possibilidade de realização de um amplo leque de mercadorias (desde as mais leves, como vestuário, até aquelas mais duráveis, como equipamentos domésticos e automóveis). [...] a inflação. [...] que não deriva apenas da emissão de títulos de crédito por estabelecimentos bancários. [...] o enorme crescimento do chamado setor terciário - ou setor de serviços, onde heterogeneamente se incluem atividades financeiras e securitárias, comerciais, publicitárias, médicas, educacionais, hoteleiras, turísticas, de lazer, de vigilância privada etc. Esse setor, onde prevalece nitidamente o trabalho improdutivo, passou a ocupar, progressivamente, uma grande massa de assa-

\footnotetext{
${ }^{5} \mathrm{O}$ estabelecimento de políticas keynesianas, de acordo com Behring e Boschetti (2009, p. 91-92), ocorreu pela conjunção de alguns fatores, como: a) estabelecimento de "pleno emprego e crescimento econômico num mercado capitalista liberal; b) instituição de serviços e políticas sociais com vistas a criar demanda e ampliar o mercado de consumo; e c) um amplo acordo entre esquerda e direita, entre capital e trabalho [...].
}

lariados, muito diferenciados entre si (desde trabalhadores sem nenhuma qualificação a especialistas, técnicos e profissionais de nível universitário).

A partir do período compreendido entre os anos de 1965 e 1973, o pacto fordista-keynesiano mostrou incapaz de conter as contradições inerentes ao sistema capitalista e, com a crise do petróleo, foi divulgada a primeira grande recessão cíclica do período pós-guerras (1973-1975), fragilizando o setor financeiro mundial e alcançando os principais países capitalistas. Essa crise decorreu da decisão dos países integrantes da Organização dos Países Exportadores de Petróleo (OPEP) de aumentar o preço do petróleo e da interdição árabe às exportações do produto para o Ocidente durante a guerra com Israel, em 1973. O embargo árabe foi contra os Estados Unidos e outros países que auxiliavam Israel durante a Guerra árabe-israelense, resultando em uma alta no preço internacional do petróleo.

$\mathrm{Na}$ tentativa de superação desta crise mundial, passou a vigorar um período de reestruturação econômica e reajustes sociais e políticos que marcaram a passagem para um novo momento de acumulação do capital, designado de acumulação flexível por Harvey (2010, p. 140), que se sustenta na "flexibilidade dos processos de trabalho, dos mercados de trabalho, dos produtos e padrões de consumo".

O novo padrão de acumulação capitalista caracteriza-se: a) pela produção flexível e em pequenos lotes de uma variedade de tipos de produto, que elimina a necessidade de estoques ${ }^{6}$ porque se volta para a demanda ${ }^{7}$; b) círculos de controle de qualidade (CCQ), integrado ao processo produtivo que realização a detecção imediata de erros e rejeição de peças com defeitos, reduzindo o "tempo perdido"; c) trabalhador é obrigado a realizar múltiplas tarefas (polivalência) e retorna-se ao pagamento pessoal por meio

\footnotetext{
${ }^{6}$ Utiliza-se o sistema toytota de produção just in time, que determina a compra de matéria-prima, a produção, o transporte somente a partir da demanda, ou seja, reduz-se o custo de produção e o estoque, porque o processo de fabricação de um produto é iniciado após a venda (SILVA, 2007).

${ }^{7}$ Para produção just in time, foi desenvolvimento o método kanban, baseado num sistema de cartazes/painel que orientam as encomendas conforme a demanda. Esse sistema pode ser utilizado em toda a cadeia produtiva, sinalizando também a necessidade reposição de matéria-prima (SILVA, 2007).
} 
de um sistema detalhado de bonificações - o controle do tempo não é mais determinado pela máquina, pois exige o envolvimento do trabalhador na equipe com a vigilância determinada pelo próprio trabalhador e pela própria equipe que visam alcançar a meta para auferir a bonificação adicional a remuneração (SILVA, 2007).

Na esfera produtiva, a produção flexível, possibilita a diminuição do "chão da fábrica", pois o controle produtivo é realizado pelos próprios trabalhadores, reduzindo a contratação de gerências e supervisores e, além disso, a multifuncionalidade impõe ao trabalhador a responsabilidade por diversas funções, mas também a intensificação do processo produtivo e com a diminuição da necessidade de armazenamento, consequentemente, ocorre a restrição de novos postos de trabalho.

Com a acumulação flexível, a indústria substitui os contratos coletivos e mantém em seu quadro funcional direto empregados que são ligados a funções produtivas e/ou indispensáveis ao processo produtivo, mas flexibiliza vínculos trabalhistas a partir da terceirização ou subcontratação de atividades como vigilância, serviços gerais etc. Trata-se da chamada "externalização" das atividades fabris, que resultaram no crescimento do setor de serviços.

De acordo com Harvey (2010), a partir dessa externalização da produção, houve redução do emprego regular em decorrência do emprego em tempo parcial (part time), temporário ou subcontratado, que gerou dois grupos de trabalhadores: $1^{\circ}$ ) trabalhadores centrais, que ainda preservam emprego em tempo integral e conservam direitos trabalhistas e $2^{\circ}$ ) trabalhadores periféricos, empregados geralmente em tempo parcial, com alta taxa de rotatividade em virtude de contratos de curto prazo, que não asseguram as mesmas coberturas de seguro e níveis salariais. Harvey (2010), aponta ainda que ocorre uma transferência de custos com a manutenção de estoques, aluguel de prédios, gastos com energia elétrica, força de trabalho etc., das grandes empresas para empresas subsidiárias (agências de temporários e subcontratação).

\section{Discussão sobre precarização e desregulamentação do trabalho}

Diante deste quadro de mundialização do capital, de acumulação flexível, de desemprego estrutural comandados pela contínua busca pela acumulação do capital, que impactou fortemente a organização da classe trabalhadora e repôs a concentração do poder econômico e político próprio do estágio imperialista, surge o termo precarização do trabalho.

Um autor que define a precarização do trabalho, a partir da perspectiva marxiana é Alves (2007). Para ele, o assalariamento inerente às condições de trabalho no capital, impõe a força de trabalho uma condição sócio estrutural e histórico ontológica de alienação:

[...] ao dizermos precariedade, tratamos de uma condição sócio-estrutural que caracteriza o trabalho vivo e a força de trabalho como mercadoria, atingindo aqueles que são despossuídos do controle dos meios de produção das condições objetivas e subjetivas da vida social. A precariedade do mundo do trabalho é uma condição histórico-ontológica da força de trabalho como mercadoria (ALVES, 2007, p. 113).

Segundo o argumento do autor (idem), a subordinação do trabalho ao controle burguês determina uma condição permanente de precariedade. Para além destas condições de precariedade social, sempre presentes no âmbito do trabalho vivo, o autor refere que a precarização do trabalho corresponde a perda de direitos adquiridos no decorrer de um período de tempo, pela organização da classe trabalhadora. Alves (2007, p. 126), explica que o processo de precarização

[...] aparece sob o neologismo da flexibilização do trabalho, impõe-se não apenas por meio da perda de direitos e do aumento da exploração da força de trabalho, por meio do alto grau de extração de sobretrabalho de contingentes operários e empregados da produção social. A precarização do trabalho se explicita por meio do crescente contingente de trabalhadores desempregados supérfluos à produção do capital.

Em Alves (2007), o conceito de precarização diz respeito a um processo histórico que reflete a luta de classes entre capital e trabalho, no estágio atual. Concordamos com as reflexões de Alves, no entanto, o termo que de fato reproduz as análises contidas nesta pesquisa é desregulamentação pois entende-se que essa 
categoria de análise versa sobre a relação entre trabalho e políticas sociais.

O que ocorre não é apenas o descumprimento das normas trabalhistas vigentes, mas um complexo processo ideológico, econômico, político e social impulsionado por organismos internacionais, como Banco Mundial, Fundo Monetário Internacional, para desmontar a regulamentação trabalhista vigente com o apoio governamental.

Compreendemos a expressão desregulamentação como um complexo fenômeno que é tensionado permanentemente sob a forma salarial da sociedade burguesa, em que a precariedade do trabalho decorre da exploração da força de trabalho, mas que pressupõe, no contexto atual de acumulação do capital a articulação entre: 1) redução e/ou revogação de conquistas históricas de direitos ao trabalho e à proteção social, dos quais são exemplos as Leis de $n^{\circ} 8.949 / 94^{8}, n^{\circ}$ $9.601 / 98^{9}$ e $n^{\circ} 10.101 / 00^{10}$; e 2) reconfiguração do setor público para atender exigências do neoliberalismo por meio de atos normativos, que reordenam o campo das políticas sociais, desde a reforma do aparelho estatal ao repasse dos serviços estatais para a esfera pública não estatal e para a iniciativa privada.

Maranhão (2010), avalia que nas três últimas décadas, o capital se desenvolveu em escala mundial a partir de um sistema financeiro internacional, que forçou os Estados nacionais a privatizações, liberando setores de investimentos que eram restritos à esfera pública, além de mecanismos de desvalorização dos salários. De acordo com Maranhão (2010, p. 48-49, grifos do autor):

[...] através de uma hegemonia político-econômica da oligarquia financeira, o capital tem criado, nas últimas décadas, mecanismos

\footnotetext{
${ }^{8}$ Afirma a inexistência de qualquer vínculo empregatício entre as cooperativas e seus associados e os tomadores de serviços daquela.

${ }^{9}$ Regulamenta o contrato temporário, com redução de encargos sociais e direitos trabalhistas, como o não pagamento de multa em caso de rescisão antecipada e redução no recolhimento do FGTS.

${ }^{10}$ A Lei $n^{\circ} 10.101 / 00$ dispõe sobre a possibilidade de ganhos decorrentes de metas vinculadas ao aumento de produção, mas desvinculada da remuneração contratual em detrimento do reajuste salarial e também permite o trabalho aos domingos e feriados para o comércio em geral.
}

artificiais para gerar crises financeiras controladas e forçar a transferência de ativos públicos ou domésticos para as mãos das transnacionais.

A cada nova crise financeira, o receituário do Fundo Monetário Internacional e do Banco Mundial é empreendido pelos Estados nacionais com maior energia, liberalizando a economia dos países, reforçando a dependência financeira através da dívida interna e externa (com a ajuda de juros extorsivos), limitando os investimentos governamentais no serviço público, privatizando os bens, serviços e fundos públicos, desenvolvendo novas formas de investimentos externos diretos e concentrando nas mãos das transnacionais uma grande quantidade de capital que antes era de domínio coletivo.

[...] Toda essa expropriação empreendida pelo capital não só liberou ativos públicos para serem reinvestidos no circuito privado de mercadorias. No interior desse processo, também foram desenvolvidos mecanismos que possibilitaram a liberação, a baixo custo, da mercadoria mais importante para o processo de valorização do capital, a força de trabalho.

Nesse complexo processo, ocorre também o aumento da população desempregada e também da inserção de camadas de trabalhadores em ocupações sem carteira assinada. Para demonstrar a parcela significativa de trabalhadores sem carteira assinada no Brasil e sua incidência, principalmente no setor de serviços, seja na área pública ou privada, utilizamos a tabela 1, a seguir.

TABELA 1 - Distribuição dos assalariados sem carteira dos setores público e privado ${ }^{(1)}$, segundo setor de atividade, Brasil, 1999 e 2009 (\%)

\begin{tabular}{c|c|c}
\hline Setor de Atividade & $\mathbf{1 9 9 9}^{(2)}$ & $\mathbf{2 0 0 9}^{(2)}$ \\
\hline${\text { Assalariados sem } \text { carteira }^{(3)}}^{(100,0}$ & 100,0 \\
\hline Indústria & 17,7 & 14,0 \\
\hline Construção civil & 5,7 & 5,4 \\
\hline Comércio & 18,0 & 17,0 \\
\hline Serviços & 57,2 & 62,5 \\
\hline
\end{tabular}

Fonte: Elaboração própria a partir DIEESE/Seade, MTE/ FAT e convênios regionais. PED - Pesquisa de Emprego e Desemprego.

Nota: (1) Excluem os assalariados terceirizados; (2) Correspondem ao total das Regiões Metropolitanas de Belo Horizonte, Porto Alegre, Recife, Salvador, São Paulo e o Distrito Federal; (3) Inclusive outros setores não selecionados. 
As tendências de ampliação do setor de serviços, a partir de condições de remuneração ou contratação sem as garantias legais, enunciadas por Harvey (2010) e Antunes (2007), se confirmam no Brasil, entre os anos 1999 e 2009. Mas na economia mundial, os direitos dos trabalhadores, vem sendo desregulamentados, após o período dos "trinta anos gloriosos" entre 1945 a 1975 pela adesão ao ideário neoliberal, denominado por Mishra (1995), de desmonte do Welfare State, a partir de três pilares: pleno emprego; universalização dos direitos sociais e piso socioeconômico mínimo, acima da miséria, abaixo do qual ninguém deveria viver. Pereira (2012, p. 737), afirma que a materialização do neoliberalismo ocorre nas afirmativas

[...] do livre mercado; das privatizações do patrimônio público; da flexibilização laboral; da negação dos direitos sociais; da substituição das políticas universais pelas focalizadas; da transformação da seguridade social em simples seguro, com descarte da assistência; e da primazia do mérito empreendedor dos indivíduos em detrimento dos direitos.

Para o Brasil, a efetividade destas medidas resultou numa incompletude da Seguridade Social tal como protagonizada no Art. 194 da Constituição de 1988, na garantia de direitos universais compostos pelo tripé Previdência, Saúde e Assistência Social. Ressalta-se, no entanto, que a desregulamentação não ocorre apenas para os trabalhadores da esfera produtiva, mas também nos contratos públicos, para o reajuste dos Estados Nacionais.

Após a Constituição "Cidadã" de 1988, no governo Fernando Henrique Cardoso (19942002), atendendo ao ajuste internacional delineado pelo Consenso de Washington, foi proposta a reforma do aparelho do Estado". O resultado da "reforma" foi um profundo processo de retrocesso social das conquistas no campo dos direitos sociais, e por isso, caracterizada por Behring (2009) como contrarreforma do Estado, convertida em um redirecionamento das políticas sociais, com graves repercussões para as condições de trabalho

[...] na medida em que aumenta a demanda por benefícios e serviços exponencialmente com o aumento da desigualdade e da pauperização absoluta e relativa, no mesmo passo em que diminuem as condições de atendimento físicas, éticas e técnicas, o que incluem impactos também na remuneração do funcionalismo público (idem, p. 317).

Sob a proposta de reforma do Estado, surge a Reforma Gerencial do Aparelho do Estado que objetiva reduzir os custos dos serviços prestados aos cidadãos e introduzir novas formas de gerenciamento da sua força de trabalho e o Plano Diretor da Reforma do Aparelho do Estado (PDRAE) que prevê a extinção de atividades e cargos considerados auxiliares ou sua "descentralização/flexibilização" em outras funções que não "envolvem o exercício do poder do Estado" (BRASIL, 1995, p. 12).

Souza (2009) afirma que a contrarreforma teve como ênfase central a superação das "formas tradicionais" da administração pública alterando o sentido da política social contido na Constituição Cidadã: permitiu-se que os serviços de saúde e educação e assistência social, fossem contratados e executados por organizações públicas não estatais competitivas; assim como também as despesas com a força de trabalho foram reduzidas por meio da terceirização.

Um dos objetivos da contrarreforma do Estado consiste na reorganização de uma política de recursos humanos capaz de superar a suposta "rigidez protecionista" atribuída às relações trabalhistas. Assim, Cavalcante e Prédes afirmam que o principal marco legal da contrarreforma que se efetiva no Brasil, desde a década de 1990, encontra-se a Ementa Constitucional 19/1998, que incide em três blocos:

[...] regras voltadas à redução de custos e à eliminação do déficit público, que englobam normas sobre o controle de gastos com pessoal, normas sobre remuneração e sobre a estabilidade do servidor público; regras para a eficiência administrativa, através de normas de flexibilização da admissão de pessoal, normas sobre a profissionalização da administração e normas sobre a flexibilização na gestão pública; regras de participação e regras de controle referentes à transparência e à participação (Cavalcante e Prédes, 2010, p. 12, grifos nossos).

No contexto de contrarreforma do Estado, diversas políticas sociais foram limitadas e, de modo particular, o desenvolvimento da seguridade 
social foi submetido a diversas pressões: regulamentação tardia, tensão entre universalidade e seletividade, forma de implementação e composição de equipes de referência com contratos de trabalho sem vínculo permanente, entre outras.

Entre as políticas de seguridade social, decidimos analisar a desregulamentação (precarização) no trabalho de assistentes sociais, a partir de sua inserção na Política de Assistência Social, pois com o processo de implementação do Sistema Único de Assistência Social (SUAS) ocorreu uma grande expansão de postos de trabalho nessa área e, também, podemos analisar estatísticas oficiais acerca das condições dos trabalhadores a partir de duas pesquisas nacionais (IBGE e MDS).

\section{Condições de trabalho de assistentes sociais na Política de Assistência Social}

De acordo com Perfil dos Municípios Brasileiros/Assistência Social 2013 do Instituto Brasileiro de Geografia e Estatística (IBGE) o total de trabalhadores na área de assistência social, no ano de 2009 , correspondia a 182.436 pessoas, ou $3,2 \%$ de todo pessoal ocupado nas administrações públicas municipais. Em 2013, o número de pessoas era de 244.683 , sendo $37,3 \%$ na região Nordeste; $29,6 \%$ na região Sudeste; $13,5 \%$ na região Sul; $10,2 \%$ na região Norte e 9,4\% concentrava-se na região Centro-Oeste. Para Cavalcante e Prédes (2010), com a EC 19/1998 ocorreram estratégias de reestruturação do setor público que provocaram rebaixamento salarial e não reconhecimento de direitos trabalhistas e previdenciários aos trabalhadores públicos. Entre estas mudanças, cita-se, principalmente, o fim do regime jurídico único (que demonstra-se no gráfico 1 e na tabela 2, abaixo), o fim da isonomia salarial e fim da estabilidade.

Observa-se a partir do gráfico 1, a seguir que desregulamentação do trabalho também se inscreve na política de assistência social, pois apesar de constante crescimento no número total de trabalhadores, no ano de 2013, trabalhadores estatutários e regidos pela Consolidação das Leis do Trabalho (CLT) representavam um total de $44,2 \%$, enquanto que somente comissionados, sem vínculos permanentes e estagiários equivalia a $55,7 \%$.

GRÁFICO 1 - Pessoal ocupado na assistência social, por vínculo empregatício, Brasil, 2005 a 2013

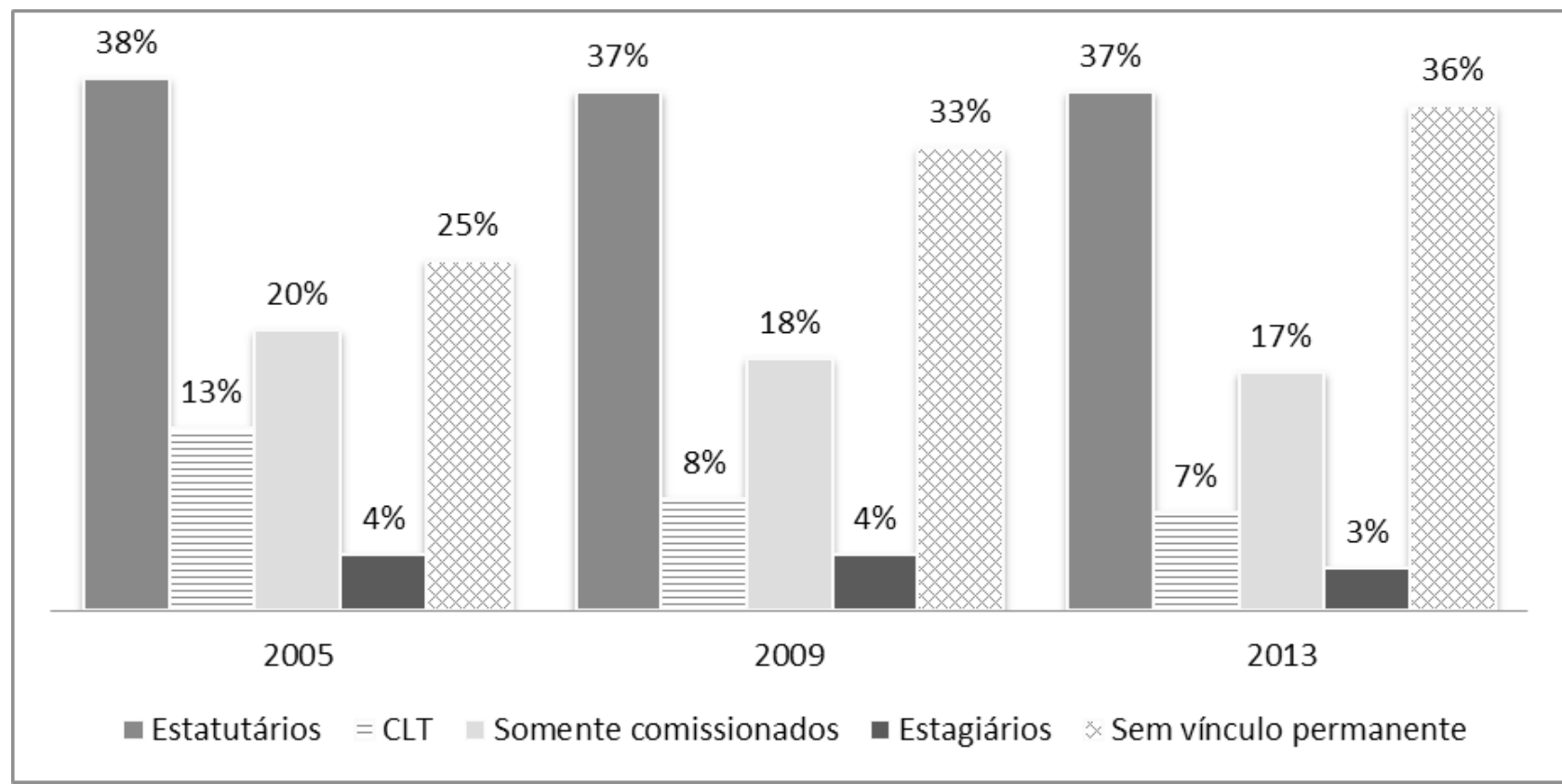

Fonte: Elaboração própria a partir do Munic 2013, IBGE. 
O gráfico 1, exemplifica o estabelecimento de mais de um regime jurídico de relações do trabalho e, consequente, que o acréscimo no número total dos trabalhadores na Política de Assistência Social, se efetiva por meio de contratos provisórios e que esta modalidade de contratação, torna-se central. A tabela 2, abaixo revela os vínculos empregatícios por grandes regiões do Brasil.
Com a tabela 2, analisa-se que, com exceção das regiões Sul e Sudeste, nas demais regiões o número de pessoal ocupado na política de assistência social, em cargos somente comissionados, estágios e sem vínculo permanente excede o quantitativo de pessoas com contratos regidos pela CLT e estatutários.

TABELA 2 - Pessoal ocupado na assistência social, por vínculo empregatício, 2013

\begin{tabular}{c|c|c|c|c|c}
\hline Grandes Regiões & Estatutários & CLT & $\begin{array}{c}\text { Somente } \\
\text { comissionados }\end{array}$ & Estagiários & Sem vínculo permanente \\
\hline Norte & 9.177 & 978 & 4.292 & 442 & 9.951 \\
\hline Nordeste & 21.875 & 4.239 & 15.948 & 1.312 & 47.942 \\
\hline Sudeste & 29.801 & 8.495 & 9.865 & 3.368 & 20.974 \\
\hline Sul & 19.456 & 2.659 & 4.847 & 2.600 & 3.489 \\
\hline Centro-Oeste & 10.823 & 652 & 5.596 & 549 & 5.353 \\
\hline
\end{tabular}

Fonte:Elaboração própria a partir do Munic 2013, IBGE.

Para o conjunto CFESS/CRESS/ABEPSS, a precarização das relações de trabalho, apresentam-se não apenas nas formas de contratação da força de trabalho, mas também por meio de dimensões: ausência de condições materiais, institucionais e financeiras necessárias ao atendimento às demandas dos usuários da política de assistência social; ausência de meios e instrumentos necessários ao exercício profissional e; a não instituição de um quadro de trabalhadores especializados, constituindo a alta rotatividade e descontinuidade dos serviços prestados (CFESS, 2011).

Em todas as Grandes Regiões brasileiras, na Política de Assistência Social, o maior número de trabalhadores possui apenas o ensino médio, seguida por profissionais com ensino superior, sendo $21,13 \%$ na região Norte; $22,67 \%$ na região Nordeste; $34,19 \%$ na região Sudeste; $28,49 \%$ na região Sul e $26,04 \%$ na região Centro-Oeste.

TABELA 3 - Pessoal ocupado na assistência social, por escolaridade em 2013.

\begin{tabular}{c|c|c|c|c|c}
\hline Grandes Regiões & $\begin{array}{c}\text { Sem } \\
\text { instrução }\end{array}$ & $\begin{array}{c}\text { Ensino } \\
\text { fundamental }\end{array}$ & Ensino médio & $\begin{array}{c}\text { Ensino } \\
\text { superior }\end{array}$ & Pós-graduação \\
\hline Norte & 707 & 4.663 & 13.508 & 5.251 & 722 \\
\hline Nordeste & 1.434 & 12.234 & 50.945 & 20.150 & 4.120 \\
\hline Sudeste & 706 & 11.335 & 31.314 & 24.729 & 4.247 \\
\hline Sul & 214 & 5.091 & 14.449 & 9.416 & 3.883 \\
\hline Centro-Oeste & 316 & 4.259 & 10.699 & 5.875 & 1.410 \\
\hline
\end{tabular}

Fonte: Elaboração própria a partir do Munic 2013, IBGE.

A pesquisa do IGBE, não permite a análise do número exato de assistentes sociais contratados na Política de Assistência Social, apenas de sua inserção enquanto gestores com ensino superior e pós-graduação. Este índice chega a $30,25 \%$ em todo o Brasil. A partir da tabela 4, constatamos a precarização da infraestrutura, que reflete diretamente nas condições de trabalho do assistente social, conforme CFESS (2011).

Mais uma vez, os dados estatísticos da Munic/IBGE, são obtidos apenas pelo órgão gestor da assistência social. No entanto, por sua centralidade no processo de atendimento às demandas da população usuária da Política 
de Assistência Social, constata-se muitas situações de precariedade, como a ausência de linha telefônica em 110 municípios na região Norte e em 395 municípios na região Nordeste e também em todo o território nacional, além de inúmeros municípios que não possuem nenhum tipo de meio de locomoção das equipes.

TABELA 4 - Características municipais da infraestrutura do órgão gestor da assistência social, 2013

\begin{tabular}{|c|c|c|c|c|c|c|c|c|c|c|c|}
\hline \multirow{2}{*}{$\begin{array}{l}\text { Grandes } \\
\text { Regiões }\end{array}$} & \multicolumn{4}{|c|}{ Telefone } & \multicolumn{3}{|c|}{ Meios de locomoção } & \multicolumn{4}{|c|}{$\begin{array}{l}\text { Computadores em } \\
\text { funcionamento }\end{array}$} \\
\hline & $\begin{array}{c}\text { Linha } \\
\text { telefônica } \\
\text { instalada }\end{array}$ & $\begin{array}{l}\text { Somente } \\
\text { ramal }\end{array}$ & $\begin{array}{l}\text { Linha } \\
\text { Tel. e } \\
\text { ramal }\end{array}$ & $\begin{array}{l}\text { Nenhum } \\
\text { dos dois }\end{array}$ & Veículos & Embarcações & $\begin{array}{l}\text { Nenhum } \\
\text { dos dois }\end{array}$ & Nenhum & $\begin{array}{l}\text { De } 1 \\
\text { a } 3\end{array}$ & $\begin{array}{l}\text { De } 4 \\
\text { a } 10\end{array}$ & $\begin{array}{l}\text { Mais } \\
\text { de } 10\end{array}$ \\
\hline Norte & 239 & 51 & 50 & 110 & 228 & 17 & 214 & 1 & 141 & 228 & 80 \\
\hline Nordeste & 866 & 250 & 282 & 395 & 1.136 & 4 & 656 & 7 & 695 & 845 & 246 \\
\hline Sudeste & 884 & 185 & 533 & 66 & 1.225 & 1 & 443 & 5 & 746 & 639 & 278 \\
\hline Sul & 502 & 208 & 468 & 11 & 874 & 2 & 315 & 2 & 548 & 500 & 139 \\
\hline $\begin{array}{l}\text { Centro- } \\
\text {-Oeste }\end{array}$ & 228 & 63 & 164 & 12 & 307 & 2 & 160 & 2 & 205 & 178 & 82 \\
\hline
\end{tabular}

Fonte: Elaboração própria a partir da Munic 2013, IBGE.

A Norma Operacional Básica de Recursos Humanos dos SUAS (NOB-RH/2006), prevê a formação de equipes de referências para o atendimento e o acompanhamento das famílias referenciadas aos Centros de Referência de Assistência Social (CRAS). No entanto, mesmo com o expressivo aumento do número de pessoas que trabalham na Política de Assistência Social, devido ao desemprego estrutural e a pauperização de classes trabalhadoras, vistas anteriormente, contribuíram para expansão de uma imensa população que precisa ser atendida pelos serviços ofertados.

A tabela 5 aborda essa diferença entre o público-alvo e todos trabalhadores da política de assistência social ${ }^{11}$. Têm-se o número de famílias referenciadas aos CRAS, e a capacidade de atendimento das famílias em dois dos principais serviços, o Serviço de Proteção e Atendimento Integral à Família (PAIF) e o Serviço de Convivência e Fortalecimento de Vínculos (SCFV).

TABELA 5 - Comparação entre Famílias referenciadas, capacidade de atendimento das famílias pelo PAIF e Pelo SCFV e pessoal ocupado na Assistência Social, Grandes Regiões, 2013.

\begin{tabular}{c|c|c|c|c}
\hline Grandes Regiões & $\begin{array}{c}\text { Famílias } \\
\text { Referenciadas }\end{array}$ & $\begin{array}{c}\text { Capacidade de } \\
\text { atendimento das famílias } \\
\text { PAIF }\end{array}$ & $\begin{array}{c}\text { Capacidade de atendimento } \\
\text { SCFV (crianças, adolescentes, } \\
\text { idosos, PCD) }\end{array}$ & $\begin{array}{c}\text { Pessoal ocupado na } \\
\text { assistência social (1) }\end{array}$ \\
\hline Norte & 2.182 .750 & 376.455 & 170.990 & 24.915 \\
\hline Nordeste & 8.896 .500 & 1.550 .036 & 682.120 & 91.248 \\
\hline Sudeste & 8.392 .625 & 1.430 .741 & 427.470 & 72.503 \\
\hline Sul & 4.476 .875 & 686.254 & 241.080 & 33.052 \\
\hline Centro-Oeste & 1.982 .500 & 1.982 .500 & 121.000 & 22.973 \\
\hline
\end{tabular}

Fonte: Elaboração própria a partir do Relatório de Informações Sociais/MDS, 2013 e Munic/IBGE, 2013.

(1) Total de pessoas ocupadas na Política de Assistência Social, independente de tipos de vínculos e escolaridade.

${ }^{11}$ Com estes dados da Munic 2013, têm-se todo o pessoal ocupado na política de assistência social, seja na Proteção Social Básica, seja na Proteção Social Especial. 
Agrande demanda (muitas vezes inespecífica) reduz o exercício profissional a um plantão emergencial e ações isoladas que não viabiliza a autonomia do assistente social, nem fortalece a participação dos usuários nos espaços de controle social democrático. Esta intervenção fragmentada encobre o horizonte do comprometimento do assistente social com os objetivos do projeto ético político ${ }^{12}$, principalmente, em sua dimensão ao estímulo a organização coletiva em defesa dos direitos sociais. Em outras palavras, o fracionamento exigido no espaço socioinstitucional dos CRAS, favorece uma suposta dissociação entre projeto ético político profissional e projeto societário.

O contexto mais geral de precarização que atravessa as condições do exercício profissional do assistente social, também incide em outros aspectos, bem mais aparentes como, por exemplo, o ambiente físico (a convivência com salas sem condições de sigilo, ausência de condições de registro etc) e a restrição das atribuições e competências profissionais ao controle/vigilância e utilização de critérios de acessibilidade aos usuários, que limitam os direitos sociais e reforçam o caráter seletivo. Além dessas condições que garantem a qualidade no exercício profissional, para fins deste artigo, apenas cita-se, que no ambiente de atuação devem também ser asseguradas condições éticas, técnicas e financeiras (para o atendimento às demandas dos usuários).

\section{Considerações Finais}

A lógica da precarização do trabalho invadiu a esfera cotidiana do exercício profissional do assistente social, desde a sua contratação profissional à infraestrutura e atendimento aos usuários de forma a impor uma rotina do emergencial, da pontualidade e do imediatismo. A ação profissional fica restrita no viés do cotidiano e desconsidera a atitude interventiva que visa o fortalecimento do protagonismo da classe

\footnotetext{
${ }^{12}$ De acordo com Teixeira e Braz (2009), o projeto ético-político articula-se a um determinado projeto societário que objetiva a construção de uma nova ordem social sem exploração de classe, gênero e etnia. Ademais, Netto (1999) explica que o projeto ético-político apresenta uma autoimagem da profissão, com valores, objetivos, funções etc., legitimados socialmente e que orientam as bases das suas relações com usuários, outras profissões e com organizações e instituições públicas e privadas.
}

trabalhadora usuária da assistência social em busca da consolidação dos direitos.

A contrarreforma do Estado na dimensão da seguridade social é comprovada à medida que esta se afasta cada vez mais da consolidação dos direitos sociais (educação, saúde, trabalho, moradia, lazer, segurança, previdência e assistência social) previstos no artigo $6^{\circ}$ da Constituição Federal "de modo a conformar um amplo sistema de proteção social, que possa garantir mudanças efetivas nas perversas condições de vida da classe trabalhadora" (CFESS, 2011, p. 1).

Concorda-se também com o CFESS (2011) sobre a precarização do trabalho na Política de Assistência, de que a inegável expansão do quadro de trabalhadores não vem garantindo o vínculo permanente com esta política, resultando em alta rotatividade e descontinuidade dos serviços. Cabe mencionar, ainda, que o quadro reduzido de assistentes sociais frente às inúmeras demandas que se materializam nessa esfera prioriza $\mathrm{o}$ atendimento de demandas emergenciais em detrimento das atividades de orientação social, na perspectiva da garantia de acesso aos direitos desta coletividade.

A precarização dos trabalhadores da assistência social se origina num quadro mais geral de desregulamentação: 1) reestruturação produtiva que flexibiliza as relações de trabalho; 2) contrarreforma do Estado; 3) desmonte da seguridade social. Suas consequências mais evidentes ao assistente social são: ampliação do número de trabalhadores com contratos precários, implicando em alta rotatividade; rebaixamento salarial; descontinuidade dos serviços socioassistenciais; impossibilidade de exercerem sua práxis profissional com autonomia e liberdade, balizados nas habilidades e competências regulamentadas em consonância com o projeto ético-político da profissão.

\section{Referências}

ALVES, Giovanni. Dimensões da Reestruturação Produtiva: ensaios de sociologia do trabalho. 2. ed. Londrina: Praxis; Bauru: Canal 6, 2007.

ANTUNES, Ricardo. Adeus ao trabalho?: Ensaio sobre as metamorfoses e a centralidade do mundo do trabalho. 12. ed. São Paulo: Cortez; Campinas: Editora da Universidade Estadual de Campinas, 2007. 
BRASIL. Ministério do Desenvolvimento Social e Combate à Fome. Censo SUAS 2010: CRAS, CREAS, Gestão Municipal, Gestão Estadual, Conselho Municipal, Conselho Estadual, Entidades Beneficentes. Brasília: MDS, Secretaria de Avaliação e Gestão da Informação; Secretaria Nacional de Assistência Social, 2011.

BRASIL. Presidência da República - Câmara da Reforma do Estado. Plano Diretor da Reforma do Aparelho do Estado. Brasília, 1995.

BRASIL. Ministério do Planejamento, Orçamento e Gestão - Instituto Brasileiro de Geografia e Estatística (IBGE). Pesquisa de Informações Básicas Municipais: Perfil dos Municípios Brasileiros Assistência Social 2009. Rio de Janeiro: IBGE, 2010.

BRAVERMAN, Harry. Trabalho e capital monopolista: a degradação do trabalho no século XX. Tradução de Nathanael C. Caixeiro. Rio de Janeiro: Guanabara, 1987.

BEHRING, Elaine Rossetti. Brasil em ContraReforma: desestruturação do Estado e perda de direitos. São Paulo, Cortez, 2003.

BEHRING, Elaine Rossetti. A política social no contexto da crise capitalista. In: Serviço Social: direitos e competências profissionais. Brasília: CFESS/ABEPSS, 2009. p. 301-321.

CAVALCANTE, Girlene M. M.; PRÉDES, Rosa. A precarização do trabalho e das políticas sociais na sociedade capitalista: fundamentos da precarização do trabalho do assistente social. Libertas, Juiz de Fora, v. 10, p. 1-24, jan.-jun. 2010.

CFESS. Trabalhar na assistência social em defesa dos direitos da seguridade social: contribuições do conjunto CFESS-CRESS ao debate sobre definição de Trabalhadores da Assistência Social. Brasília: CFESSCRESS, 2011.

CFESS. O perfil profissional do assistente social no Brasil.

FERREIRA, Stela da Silva. NOB-RH Anotada e Comentada. Brasília: MDS; Secretaria Nacional de Assistência Social, 2011.

HARVEY, David. Condição pós-moderna: uma pesquisa sobre as origens da mudança cultural. Tradução de Adail Ubirajara Sobral e Maria Stela Gonçalves. 19. ed. São Paulo: Loyola, 2010.

MARANHÃO, Cézar Henrique. Capital e superpopulação relativa: em busca das raízes contemporâneas do desemprego e do pauperismo.
In: BEHRING, Elaine R.; ALMEIDA, Maria Helena T. (orgs.). Trabalho e Seguridade social: percursos e dilemas. 2. ed. São Paulo: Cortez; Rio de Janeiro: FSS/UERJ, 2010. p. 38-58.

MARX, Karl. O Capital: crítica da economia política. Tradução de Regis Barbosa e Flávio R. Kothe. São Paulo: Nova Cultural, 1996. Livro I. (Os economistas).

MATTOSO, Jorge Eduardo Levi. A desordem do trabalho. São Paulo: Páginas Abertas, 1996.

MISHRA, Ramesh. O Estado-providência na sociedade capitalista: estudo comparativo das políticas públicas na Europa, América do Norte e Austrália. Tradução de Ana Barradas. Oeiras: Celta, 1995.

NETTO, J. P. A construção do projeto ético político contemporâneo. In: Capacitação em Serviço Social e Política Social. Módulo 1. Brasília: CEAD/ABEPSS/ CFESS, 1999.

PEREIRA, Potyara Amazoneida P. Utopias desenvolvimentistas e política social no Brasil. Serviço Social \& Sociedade, São Paulo, n. 112, p. 729-754, out./dez. 2012.

SILVA, Christiane Pimentel. Organização e socialização da produção na Associação Mutirão: município de Igarapé-Miri/PA. 2007. 91 f. Trabalho de Conclusão de Curso. Faculdade de Serviço Social, Universidade Federal do Pará, Belém, 2007.

SILVA, Christiane Pimentel. Marx e o imperativo da mais-valia. 2010. 92 f. Dissertação (Mestrado) - Programa de Pós-Graduação em Serviço Social, Universidade Federal do Pará, Belém, 2010.

SOUZA, Moema S. L. O trabalho em saúde: os fios que tecem a (des)regulamentação do trabalho nos serviços públicos. 2009. 257 f. Tese (Doutorado) Programa de Pós-Graduação em Serviço Social, Universidade Federal de Pernambuco, Recife, 2009.

TEIXEIRA, Joaquina B.; BRAZ, Marcelo. O projeto ético-político do Serviço Social. In: CFESS/ABEPSS. Serviço Social: direitos sociais e competências profissionais. Brasília: CFESS/ABEPSS, 2009. p. 185-199.

VASCONCELOS, Ana Maria de. Serviço Social e prática reflexiva. Em Pauta, Rio de Janeiro, n. 10, p. 131-181, jul. 1997. 